\title{
FINITE ELEMENT ANALYSIS OF LONG-TIME AGING AND SUDDEN ACCIDENTAL DEGENERATION OF LUMBAR SPINE SEGMENTS IN COMPRESSION
}

Márta Kurutz ${ }^{1}$, László Oroszváry ${ }^{2}$

${ }^{1}$ Budapest University of Technology and Economics

${ }^{2}$ Knorr Bremse Hungaria Ltd

kurut2m@eik.bme.bu

\begin{abstract}
3D finite element analysis of long term aging and sudden accidental degeneration processes is presented for physiologic compression load. A systematic modeling and simulation is applied for analyzing the separated and mutual effect of certain material moduli of the components of lumbar motion segments on the mechanical behaviour and stability of the segment during the long time and sudden degeneration processes. It was concluded that due to their smallest stiffness the younger segments with light degeneration are the most vulnerable during both the long-time age-related and the sudden overload-related degeneration.
\end{abstract}

Keywords: finite element simulation, age-related degeneration, sudden accidental degeneration, lumbar motion segment, compressive stiffness

\section{Introduction}

Numerical analyses are able to simulate biomechanical processes in their progress that are impossible to be followed experimentally, like spinal degeneration processes. Degeneration represents special and injurious changes in the structure, composition and function of spine or part of the spine, caused by aging or by certain accidental injurious effects, like a wrong movement or mechanical overloading. ${ }^{1}$

The age-related changes of spine start generally in the intervertebral discs; within the disc nucleus, altering markedly the mechanics of load transfer and spinal stability. ${ }^{2}$ The age-related changes of the disc are manifested in loss of hydration, a drying and stiffening procedure in the texture of both nucleus and annulus. ${ }^{3}$ Aging procedures are often accompanied by other kinds of degeneration: buckling, lesions, tears, fiber break in the annulus ${ }^{8,9}$ or osteoporotic changes in the vertebral bone. However, some degeneration can happen suddenly, due to some traumatic effects causing disc prolapse, endplate disruption or osteoporotic vertebral fracture. These kinds of sudden degenerations can happen at any age.

Several recent studies conclude that instability of lumbar spine happens to the younger discs, and the stability restores with further aging. ${ }^{3-5}$ Since sudden degenerations may also be dangerous in young age, further studies are necessary for understanding the biomechanical function of degeneration processes. Although FE modeling of lumbar spine focused recently to degenerations, there are no papers dealing with sudden degeneration processes. Some authors concluded that the nucleus underwent a transition from fluid-like to solid-like material during aging $^{6,7}$, or classified the grades of aging degeneration as first stiffening of the nucleus then the whole disc. ${ }^{8}$ Others ${ }^{4,9-10}$ model aging degeneration by different loss of disc height and nucleus 
compressibility, or other material properties. Others used poro-elastic FE models to simulate aging degeneration. ${ }^{11-14}$ Most of these studies concluded that the highest risk of disc prolapse was found in mildly degenerated young discs, however there are no answer to the question why.

The goal of this study was to obtain numerical conclusions for the mechanical effects of the cases of (1) normal age-related changes and (2) sudden overload-related degenerations, moreover, (3) to answer the question why the mildly degenerated young segments are more vulnerable.

The paper aims to determine the separated and mutual effect of the main mechanical degeneration phenomena, the effect of gradual decrease of incompressibility of disc nucleus and the increase of stiffness of nucleus during age-related degeneration processes. The aim was also to determine the degenerative effects of short-term sudden compressive overload and to answer the question why are the younger spine segments more vulnerable.

\section{Methods}

A 3D model of a typical lumbar segment L4-5 was created (Figure 1a) by using Pro/Engineer code. The geometry and tissue volumes were obtained by the anatomical measures of a typical lumbar segment. ${ }^{15,16}$ Cortical and cancellous bone of vertebrae was separately modeled, including posterior bony elements and facet joints. The height of the disc was considered to decrease linearly from 10 to $6 \mathrm{~mm}$ for the five aging degeneration degrees. The endplates were divided into external bony and central cartilaginous part. Accordingly, the annulus matrix was divided into internal and external ring and three layers of annulus fibers; (Figure 1b).

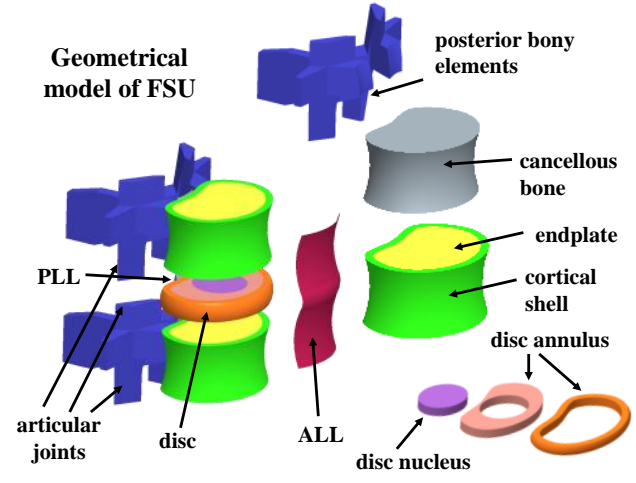

a)

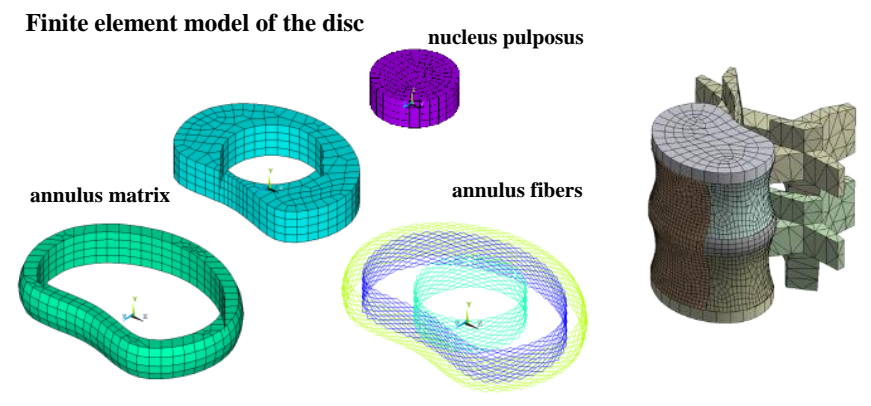

b) c)

Figure 1. Geometric and finite element model of the lumbar segment

The FE mesh was generated by ANSYS Workbench and the connections between the several geometrical components were integrated to the FE model by ANSYS Classic (Figure 1c). The FE model consisted of solid, shell and bar elements. Annulus matrix, nucleus, cancellous bone, articular joints and different types of attachments were modeled by solid elements; cortical shells and endplates were modeled by shell elements. The compatibility between the adjacent solid and shell elements was guaranteed by contact elements. All ligaments were modeled by shell elements. 


\begin{tabular}{|l|c|c|}
\hline \multicolumn{1}{|c|}{ Components of FSU } & $\begin{array}{c}\text { Young's mod } \\
{[\mathrm{MPa}]}\end{array}$ & $\begin{array}{c}\text { Poisson's } \\
\text { ratio }\end{array}$ \\
\hline vertebral cortical bone & 12000 & 0,3 \\
\hline posterior elements, facet & 3500 & 0,3 \\
\hline vertebral cancellous bone & 150 & 0,3 \\
\hline bony endplate & 12000 & 0,3 \\
\hline cartilaginous endplate & 100 & 0,4 \\
\hline nucleus & 1 & 0,499 \\
\hline annulus ground substance, internal & 4 & 0,45 \\
\hline annulus ground substance, external & 5 & 0,40 \\
\hline annulus fibers & $500 / 400 / 300^{*}$ & - \\
\hline anterior longitudinal ligament & $8^{* *}$ & 0,35 \\
\hline posterior longitudinal ligament & $10^{* *}$ & 0,35 \\
\hline other ligaments & $5^{* *}$ & 0,35 \\
\hline \multicolumn{2}{|c|}{$*$ external/middle/internal fibers, } & $* *$ tension only \\
\hline
\end{tabular}

Table 1. Material moduli of the components of healthy FSU

Table 1 shows the material moduli of healthy FSU. For the bony elements and endplates, for both tension and compression, linear elastic isotropic materials were applied, based on the literature. ${ }^{4,5,17-19}$ Annulus ground substance and nucleus were considered linear elastic for compression and bilinear elastic for tension. For the fluid-like healthy nucleus, the data of,${ }^{20-23}$ for the annulus matrix of ${ }^{15-16,24-25}$ was considered. Collagen fibers of the annulus were considered as bilinear elastic isotropic tension-only material. ${ }^{26-29}$ All the seven ligaments were integrated in the model with bilinear elastic tension-only materials of the literature again.

For the numerical simulation of age-related and sudden degeneration processes we developed a concise modeling system, seen in Table 2 containing five columns and five rows, consequently $5 \times 5=25$ main blocks, named $A i j, i, j=1,2,3,4,5$. Since the main characteristics of aging degeneration procedure of motion segments are the gradual loss of incompressibility of nucleus modeled by decreasing Poisson's ratio, and the gradual hardening of nucleus modeled by increasing Young's modulus, the main variables in Table 2 are the Young's modulus E of nucleus (in horizontal headings) and the Poisson's ratio nu of nucleus (in vertical headings). Thus, horizontally the stiffening of nucleus and annulus matrix and the weakening of cancellous bone, endplates and annulus fibers are modeled during aging; and vertically the loss of nucleus fluidity is modeled. That is, horizontally (from left to right) the long-term age-related changes, while vertically (from up to down) the sudden degenerations could be modeled separately. Moreover, the five grades of age-related degeneration process are represented in the shadowed main diagonal blocks of Table 2 (Aij, $\mathrm{i}=\mathrm{j}$ ), from the healthy (block A11) to the fully degenerated cases (block A55). Sudden degenerations were modeled by considering the actual grade of aging degeneration state in which the sudden overload happens. Based on Table 2 systematic numerical analysis could be done to analyze the separated and mutual effect of the material moduli. 


\begin{tabular}{|c|c|c|c|c|c|c|c|c|c|c|c|c|c|c|c|c|c|c|c|c|}
\hline \multirow{2}{*}{$\begin{array}{l}\begin{array}{l}\text { disc } \\
\text { height }\end{array} \\
\text { nucleus } \\
\text { Eu } \\
\text { nu }\end{array}$} & \multicolumn{4}{|c|}{$10 \mathrm{~mm}$} & \multicolumn{4}{|c|}{$9 \mathrm{~mm}$} & \multicolumn{4}{|c|}{$8 \mathrm{~mm}$} & \multicolumn{4}{|c|}{$7 \mathrm{~mm}$} & \multicolumn{4}{|c|}{$6 \mathrm{~mm}$} \\
\hline & $\begin{array}{c}1 \\
\mathbf{M P a}\end{array}$ & \begin{tabular}{|c|} 
anrubus \\
intlext \\
E/rnu \\
\end{tabular} & $\begin{array}{l}\text { canc. } \\
\text { bone } \\
\text { E/rn1 }\end{array}$ & $\begin{array}{l}\text { end- } \\
\text { plate } \\
\text { E/ru } \\
\end{array}$ & $\begin{array}{c}2 \\
\mathbf{M P a}\end{array}$ & $\begin{array}{c}\text { anrouhus } \\
\text { int/ext } \\
\text { Eirno }\end{array}$ & $\begin{array}{l}\text { carc. } \\
\text { bone } \\
\text { E/rns }\end{array}$ & \begin{tabular}{|l|} 
end- \\
plate \\
E/rns \\
\end{tabular} & $\begin{array}{c}6 \\
\mathbf{M P a}\end{array}$ & $\begin{array}{c}\text { anroubus } \\
\text { int/ext } \\
\text { E/ron } \\
\end{array}$ & $\begin{array}{l}\text { carr. } \\
\text { bone } \\
\text { E/rns }\end{array}$ & $\begin{array}{l}\text { end- } \\
\text { plate } \\
\text { E/rnu } \\
\end{array}$ & $\begin{array}{c}16 \\
\text { MPa }\end{array}$ & $\begin{array}{l}\text { amrondus } \\
\text { intlext } \\
\text { Eirnu }\end{array}$ & $\begin{array}{l}\text { carr. } \\
\text { bone } \\
\text { E/rnz }\end{array}$ & $\begin{array}{l}\text { end- } \\
\text { plate } \\
\mathrm{E} / \mathbf{u u} \\
\end{array}$ & $\begin{array}{c}36 \\
\text { MPa }\end{array}$ & $\begin{array}{c}\text { arroubss } \\
\text { intext } \\
\text { E/rns } \\
\end{array}$ & $\begin{array}{l}\text { canc. } \\
\text { bone } \\
\text { E/rnu }\end{array}$ & $\begin{array}{l}\text { end- } \\
\text { plate } \\
\text { E/ron } \\
\end{array}$ \\
\hline \multirow{4}{*}{0,499} & Al1 & & & & A12 & & & & $\overline{A 13}$ & & & & $\overline{A 14}$ & & & & Al5 & & & \\
\hline & & $\begin{array}{c}\mathbf{4 5} \\
0,450,40 \\
\end{array}$ & & & & $\begin{array}{c}45 / 6 \\
0,440,39 \\
\end{array}$ & & & & $\begin{array}{c}6599 \\
0,430,38\end{array}$ & & & & \begin{tabular}{|c|}
$115 / 7$ \\
$0,420,37$ \\
\end{tabular} & & & & $\begin{array}{c}20,29 \\
0,41036 \\
\end{array}$ & & \\
\hline & & & $\begin{array}{l}150 \\
0,3\end{array}$ & & & & $\begin{array}{l}125 \\
0.3\end{array}$ & & & & $\begin{array}{l}100 \\
0,3\end{array}$ & & & & $\begin{array}{l}75 \\
0,3\end{array}$ & & & & $\begin{array}{l}50 \\
0,3\end{array}$ & \\
\hline & & & & $\begin{array}{l}100 \\
0,4\end{array}$ & & & & $\begin{array}{l}80 \\
0,4\end{array}$ & & & & $\begin{array}{c}60 \\
0,4\end{array}$ & & & & $\begin{array}{l}40 \\
0,4\end{array}$ & & & & $\begin{array}{c}20 \\
0,4\end{array}$ \\
\hline \multirow{4}{*}{0,475} & A21 & & & & $\overline{\text { A22 }}$ & & & & A23 & & & & $\overline{A 24}$ & & & & A25 & & & \\
\hline & & $\begin{array}{c}\mathbf{4 . 5} \\
0,45 ., 40 \\
\end{array}$ & & & & $\begin{array}{c}45 / 6 \\
0,440,39 \\
\end{array}$ & & & & $\begin{array}{c}65 / 9 \\
0,430,38\end{array}$ & & & & \begin{tabular}{|c|}
$115 / 17$ \\
$0,420,37$ \\
\end{tabular} & & & & $\begin{array}{c}20,29 \\
0,410,36 \\
\end{array}$ & & \\
\hline & & & $\begin{array}{l}150 \\
0,3\end{array}$ & & & & $\begin{array}{l}125 \\
0,3\end{array}$ & & & & $\begin{array}{l}100 \\
0,3\end{array}$ & & & & $\begin{array}{l}75 \\
03 \\
\end{array}$ & & & & $\begin{array}{l}50 \\
0.3 \\
\end{array}$ & \\
\hline & & & & $\begin{array}{l}100 \\
0,4\end{array}$ & & & & $\begin{array}{l}80 \\
0,4\end{array}$ & & & & $\begin{array}{c}60 \\
0,4\end{array}$ & & & & $\begin{array}{c}40 \\
0,4\end{array}$ & & & & $\begin{array}{c}20 \\
0,4\end{array}$ \\
\hline \multirow{4}{*}{0,450} & A31 & & & & $\mathbf{A 3 2}$ & & & & $\overline{\mathrm{A33}}$ & & & & $\overline{\mathbf{A 3 4}}$ & & & & $\mathrm{A35}$ & & & \\
\hline & & $\begin{array}{c}4.5 \\
0,450,40 \\
\end{array}$ & & & & $\begin{array}{c}45 / 6 \\
0,440,39 \\
\end{array}$ & & & & $\begin{array}{c}65 / 9 \\
0,430,038 \\
\end{array}$ & & & & \begin{tabular}{|c|}
$115 / 7$ \\
0,42037 \\
\end{tabular} & & & & $\begin{array}{c}20,29 \\
0,41036 \\
\end{array}$ & & \\
\hline & & & $\begin{array}{l}150 \\
0,3\end{array}$ & & & & $\begin{array}{l}125 \\
0,3 \\
\end{array}$ & & & & $\begin{array}{l}100 \\
0,3 \\
\end{array}$ & & & & $\begin{array}{l}75 \\
0,3\end{array}$ & & & & $\begin{array}{l}50 \\
0,3 \\
\end{array}$ & \\
\hline & & & & $\begin{array}{l}100 \\
0,4\end{array}$ & & & & $\begin{array}{l}80 \\
0,4\end{array}$ & & & & $\begin{array}{c}60 \\
0,4 \\
\end{array}$ & & & & $\begin{array}{l}40 \\
0,4\end{array}$ & & & & $\begin{array}{c}20 \\
0,4 \\
\end{array}$ \\
\hline \multirow[t]{4}{*}{0,425} & \begin{tabular}{|l|} 
A41 \\
\end{tabular} & & & & \begin{tabular}{|l|l|}
$\mathbf{4 4 2}$ \\
\end{tabular} & & & & $\mathbf{A 4 3}$ & & & & \begin{tabular}{|l|l|}
$\mathbf{4 4 4}$ \\
\end{tabular} & & & & A45 & & & \\
\hline & & $\begin{array}{c}\mathbf{4 . 5} \\
0,45.0,40 \\
\end{array}$ & & & & $\begin{array}{c}45 / 6 \\
0,440,39\end{array}$ & & & & $\begin{array}{c}65 / 9 \\
0,430,38 \\
0,30\end{array}$ & & & & \begin{tabular}{|c|}
$115 / 17$ \\
$0,42 / 0,37$
\end{tabular} & & & & $\begin{array}{c}2029 \\
0,41036 \\
0,30\end{array}$ & & \\
\hline & & & $\begin{array}{l}150 \\
0,3 \\
\end{array}$ & & & & $\begin{array}{l}125 \\
0,3 \\
\end{array}$ & & & & $\begin{array}{l}100 \\
0,3\end{array}$ & & & & $\begin{array}{l}75 \\
0,3 \\
\end{array}$ & & & & $\begin{array}{l}50 \\
0,3 \\
\end{array}$ & \\
\hline & & & & $\begin{array}{l}100 \\
0,4 \\
\end{array}$ & & & & $\begin{array}{l}80 \\
0,4 \\
\end{array}$ & & & & $\begin{array}{c}60 \\
0,4 \\
\end{array}$ & & & & $\begin{array}{l}40 \\
0,4 \\
\end{array}$ & & & & $\begin{array}{c}20 \\
0,4\end{array}$ \\
\hline \multirow[t]{4}{*}{0,400} & \begin{tabular}{|l|} 
A51 \\
\end{tabular} & & & & \begin{tabular}{|l|} 
A52 \\
\end{tabular} & & & & $\mathrm{A53}$ & & & & A54 & & & & $A E 5$ & & & \\
\hline & & $\begin{array}{c}\mathbf{4 5} \\
0,45.0,40 \\
\end{array}$ & & & & $\begin{array}{c}45 / 6 \\
0,440,39 \\
\end{array}$ & & & & $\begin{array}{c}65 / 9 \\
0,430,38 \\
\end{array}$ & & & & \begin{tabular}{|c|}
$115 / 7$ \\
$0,4210,37$ \\
\end{tabular} & & & & $\begin{array}{c}20,29 \\
0,410,36 \\
\end{array}$ & & \\
\hline & & & $\begin{array}{l}150 \\
0,3\end{array}$ & & & & $\begin{array}{l}125 \\
0,3\end{array}$ & & & & $\begin{array}{l}100 \\
0,3\end{array}$ & & & & $\begin{array}{l}75 \\
0,3\end{array}$ & & & & $\begin{array}{l}50 \\
0,3 \\
\end{array}$ & \\
\hline & & & & $\begin{array}{l}100 \\
0,4 \\
\end{array}$ & & & & $\begin{array}{l}80 \\
0,4 \\
\end{array}$ & & & & $\begin{array}{l}60 \\
0,4 \\
\end{array}$ & & & & $\begin{array}{l}40 \\
0,4 \\
\end{array}$ & & & & $\begin{array}{c}20 \\
0,4 \\
\end{array}$ \\
\hline fibers & & $500 / 400 /$ & & & & $250 / 200 \pi$ & & & & $125 / 100$ & & & & $63150 / 38$ & & & & $10 / 10$ & & \\
\hline
\end{tabular}

Table 2. Systematic material modeling of age-related and sudden degenerations for numerical simulation of degeneration processes

For simulating age-related degeneration processes, $1000 \mathrm{~N}$ axial compression load was applied for all degeneration grades. For sudden traumatic degeneration processes, the $1000 \mathrm{~N}$ compression was increased to $5000 \mathrm{~N}^{3}$

Our finite element models of healthy and degenerated FSU were validated both for compression and tension. Distribution of vertical compressive stresses in the mid-sagittal horizontal section of the disc, calculated for $2000 \mathrm{~N}$ compressive load for healthy and fully aging-degenerated FSU was compared to the experimental results of Adams et al. ${ }^{3}$ obtained by stress profilometry for the same load. Degeneration caused vertical stress decrease in nucleus and internal annulus with high stress peaks in external annulus. Our numerical results were in good correspondence with the experiments of ${ }^{3,30-31}$ For axial tension, the calculated elongations of discs were compared to the in vivo measured elongations of lumbar FSU model L3-S1 in ${ }^{32}$ just after being suspended in water with $700 \mathrm{~N}$ body weight and $40 \mathrm{~N}$ extra weight in weightbath hydrotraction treatment. ${ }^{33}$ The calculated elongations of healthy and degenerated lumbar FSUs were practically the same as measured by. ${ }^{32}$

\section{Results}

Figure $2 a$ shows the mean mid-sagittal compressive strains of disc elements that were smaller at the cartilaginous endplate supported middle of disc, in nucleus, and larger at the bony endplate supported edge of disc, in external annulus. Figure $2 b$ shows the decreasing posterior, anterior and lateral disc bulging during aging. Figure $2 c$ and $2 d$ illustrate the central compressive strain of disc in terms of the separated effect of the gradual loss of incompressibility (Poisson's ratio) and gradual 
stiffening (increasing Young's modulus) of nucleus. Their mutual effect can be seen in Figure $2 a$ for nucleus, demonstrating that in the beginning period of aging, the effect of loss of nucleus incompressibility dominates, yielding maximum disc deformability in the second grade at mild degeneration, while later the effect of nucleus hardening dominates resulting significant decrease of deformations in further aging.

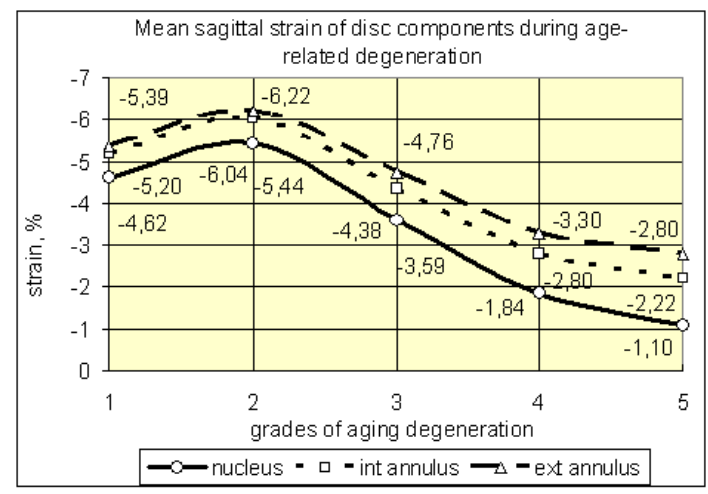

a)

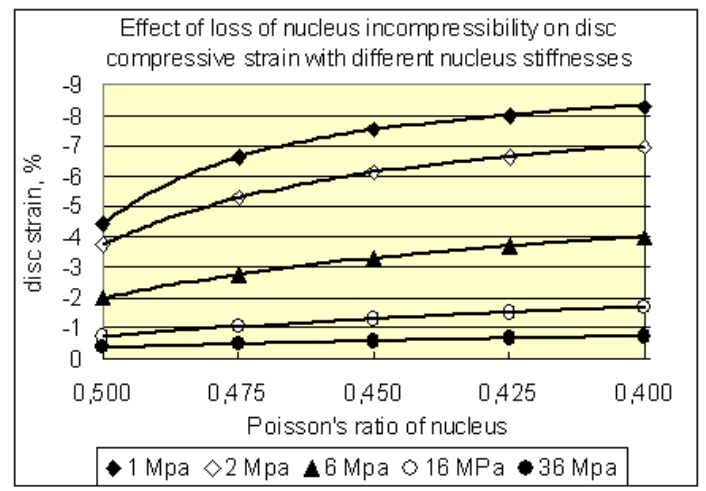

c)

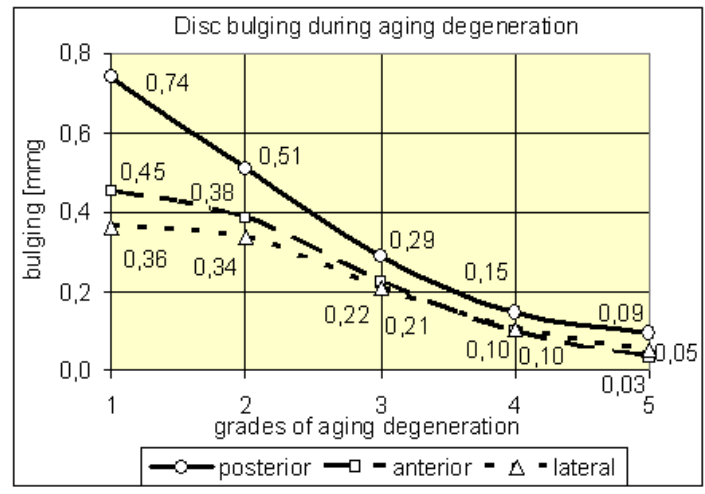

b)

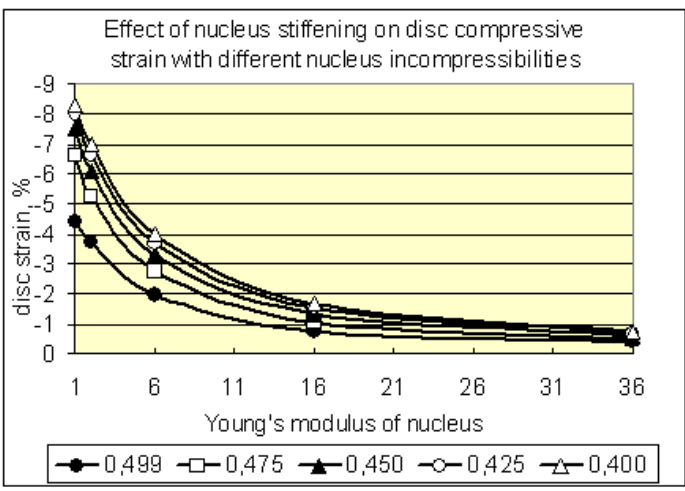

d)

Figure 2. a) Mid-sagittal compressive strains of disc components and b) sagittal disc bulging during normal aging; The separated effect of c) the decrease of Poisson ratio of nucleus and d) the increase of Young's modulus of nucleus on the central compressive strain of disc during aging.

Figure $3 a$ illustrates the mid-frontal vertical compressive stresses for the five aging grades. During aging, the gradual decrease of central and increase of external compressive stresses can be observed. Figure $3 b$ shows the mean mid-frontal compressive stresses in the nucleus, internal and external annulus, demonstrating that the compressive load transfer moves from inside to outside the disc with aging. During the total aging process the stress decrease in the nucleus was $60 \%$, in the internal annulus was 35\%, however, in the external annulus 150\% stress increase was observed. The separated effect of the decrease of Poisson ratio of nucleus (Figure 3c) and the increase of Young's modulus of nucleus (Figure 3d) on the vertical compressive stresses of nucleus demonstrated that in the beginning period of aging, the effect of loss of nucleus incompressibility dominated, causing rapid stress decrease in nucleus in the second grade, while 
later the effect of nucleus hardening dominated resulting significant stress decrease during further aging.

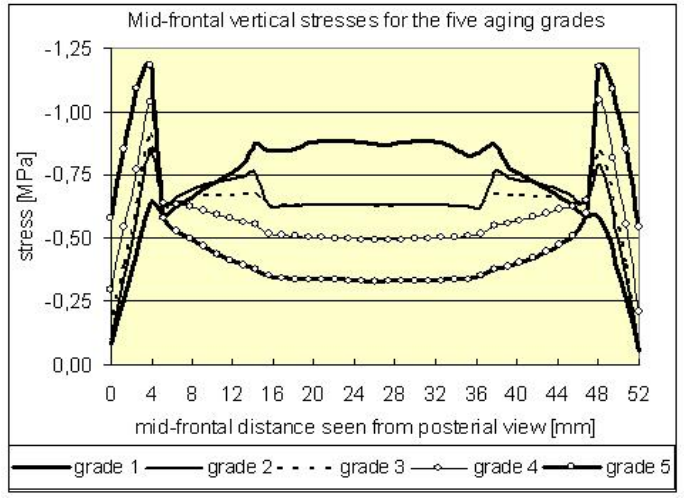

a)

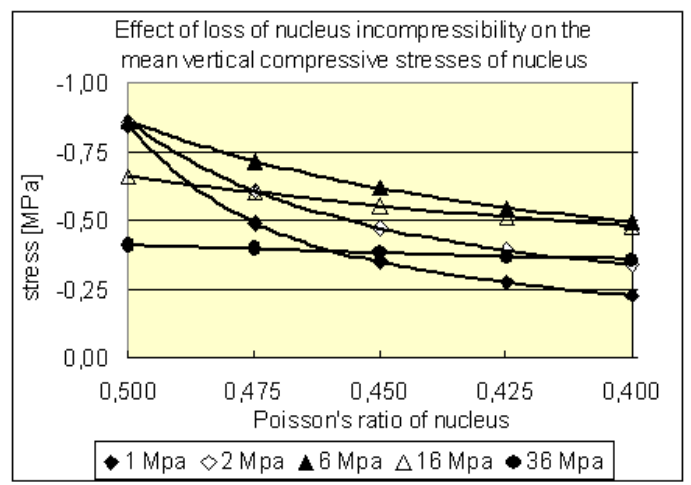

c)

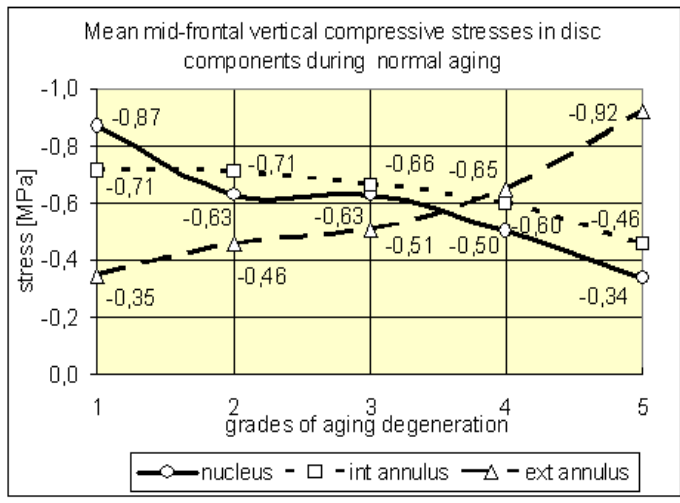

b)

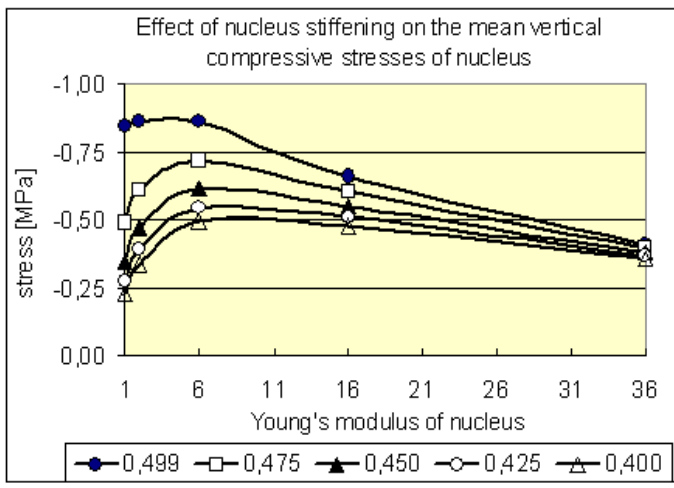

d)

Figure 3. a) Mid-frontal distribution of vertical compressive stresses for the five aging degeneration grades;

b) Change of the mean mid-frontal vertical compressive stresses of disc components during aging.

The separated effect of c) decrease of Poisson ratio of nucleus and d) increase of Young's modulus of nucleus on the vertical compressive stresses of nucleus

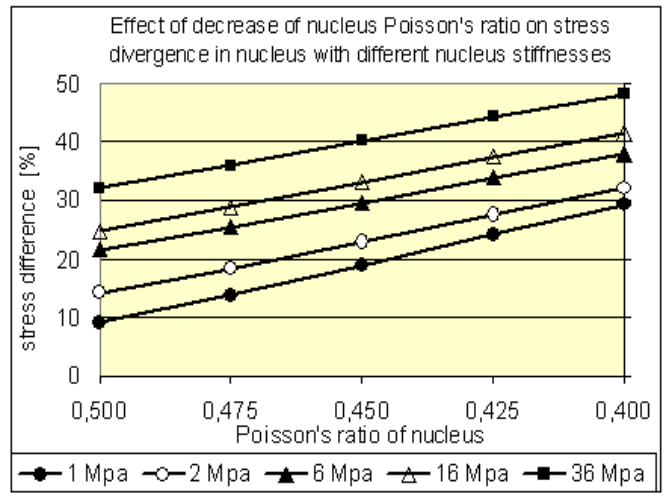

a)

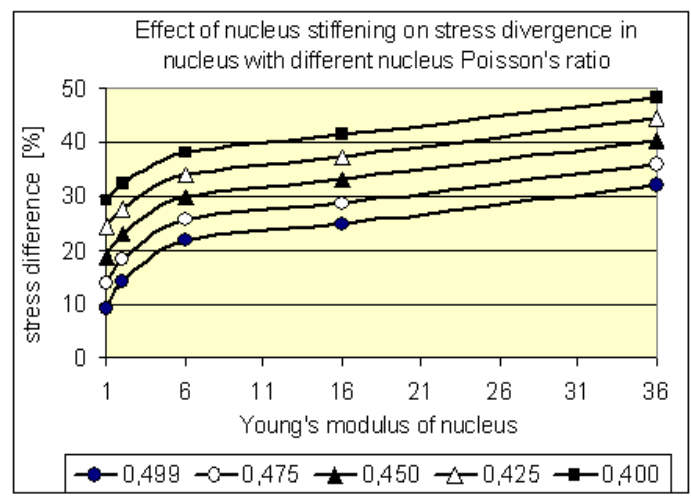

b)

Figure 4. a) The separated effect of the a) loss of nucleus incompressibility and b) nucleus hardening on the stress divergence in nucleus 
Figure $4 a$ and $4 b$ show the separated effect of the decrease of Poisson's ratio of nucleus and the increase of Young's modulus of nucleus on the stress divergence in nucleus. A healthy nucleus is in hydrostatic compression stress state, namely, the stresses in nucleus in different directions are equal. During the loss of hydrostatic stress state, the stresses start to diverge, that is, the difference among them starts to increase. Figure $4 a$ and $4 b$ demonstrates that the hydrostatic stress state needs fluid-like material with small Young's modulus.

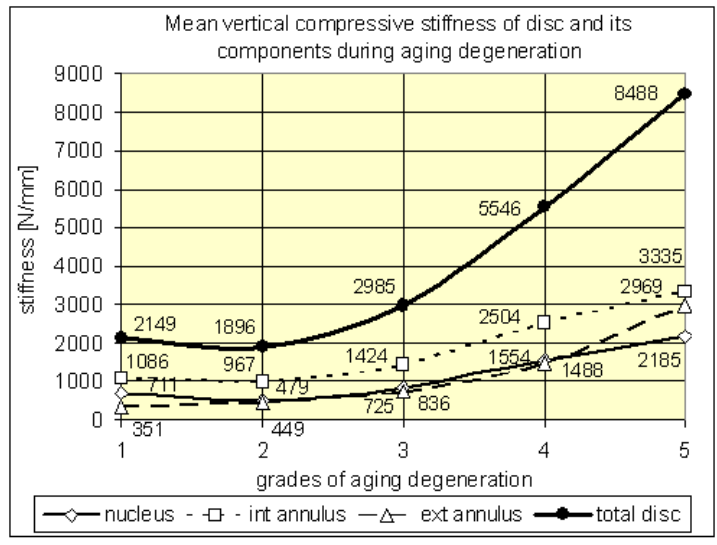

Figure 5. Change of compressive stiffness of disc components and total disc during aging degeneration

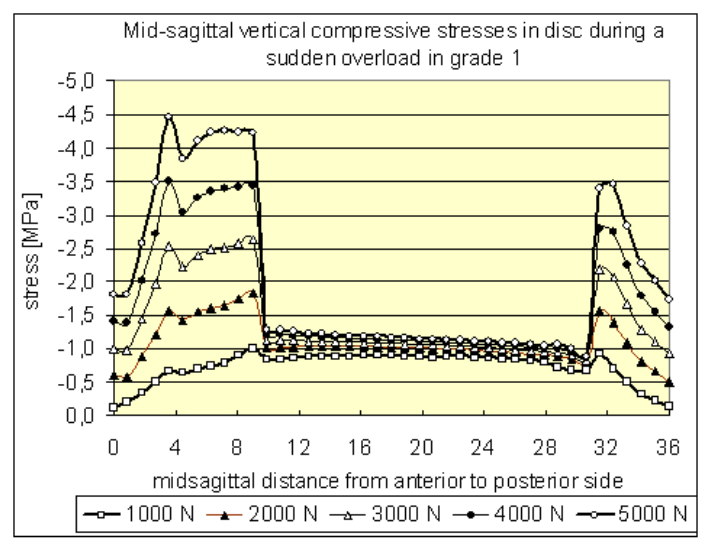

a)

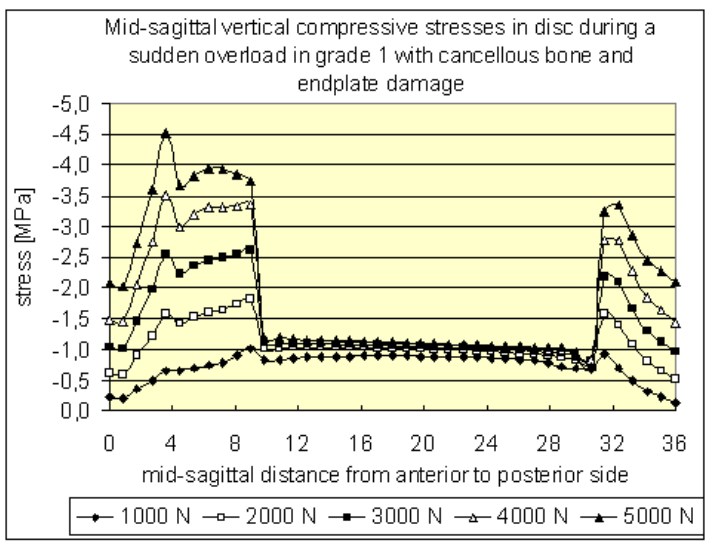

c)

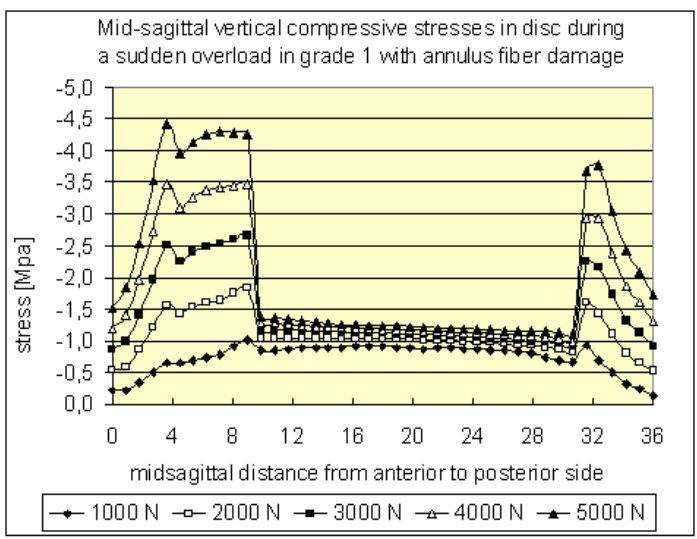

b)

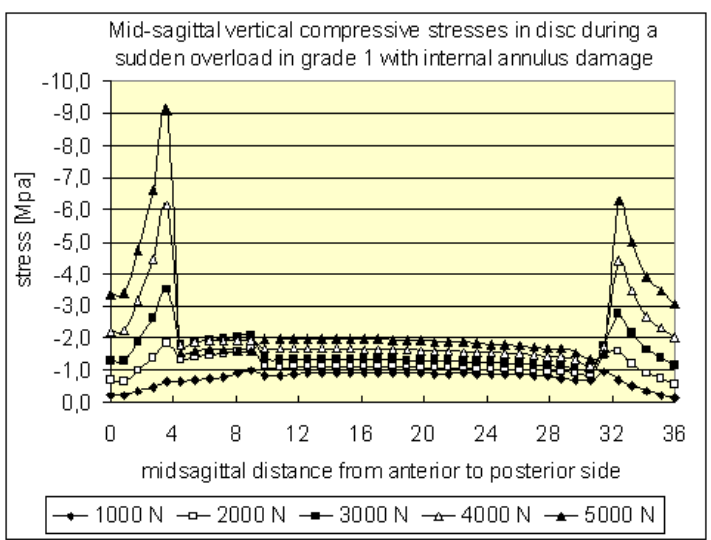

d)

Figure 6. Sudden degeneration in grade 1 with a) sudden loss of nucleus incompressibility accompanied by b) annulus fiber damage, c) vertebral cancellous bone and endplate damage, d) internal annulus damage. 
In Figure 5 the change of vertical compressive stiffness of the disc and each of its components are seen during the age-related normal degeneration procedure. The stiffness of the total disc was about $2150,1900,3000,5550$ and $8500 \mathrm{~N} / \mathrm{mm}$ in the five aging degeneration degree. It can be seen clearly that the minimum of compressive stiffness belongs to the early period of life, to the young adult age for all disc components and for the total disc.

The sudden degeneration in young age (in grade 1) was modeled by an accidental loss of hydrostatic stress state in nucleus due to a sudden overload when the nucleus quasi bursts out modeled by rapid decrease of Poisson's modulus of nucleus parallel to an accidental load increase from 1000 to $5000 \mathrm{~N}$.

Figure $6 a$ illustrates the mid-sagittal vertical compressive stress distribution in disc with sudden loss of nucleus incompressibility but all other organs are intact. In Figure $6 b$ the nucleus damage is accompanied by annulus fiber damage, in Figure $6 c$ by cancellous bone and endplate damage together, in Figure $6 d$ by internal annulus buckling.

It can be seen that during the sudden overload with nucleus damage, the vertical compressive stresses did not change in the nucleus, however, in the annulus the stresses increased extremely, by $400 \%$.

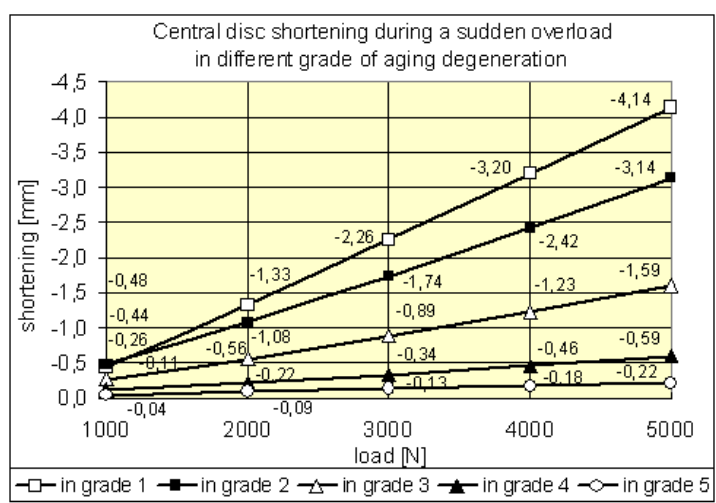

a)

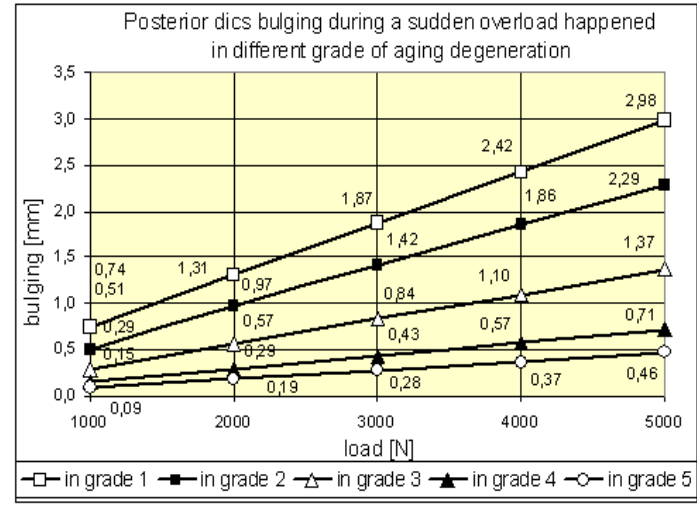

b)

Figure 7. a) Central disc shortening and b) posterior disc bulging during a sudden overload for different grade of aging degeneration

In contrast to the aging degeneration, the overload-related degeneration can happen in any time, at any age. However, the consequence of it depends highly on the actual aging grade when it happened. In Figure 7 the central disc shortening and the posterior disc bulging is illustrated in terms of the grades of normal aging degeneration when the accidental overload happened.

Figure $8 a$ shows the mid-sagittal vertical compressive stress distribution in disc when the sudden overload happens in grade 3 , in older age, accompanied by vertebral cancellous bone and endplate damage. In Figure $8 b$ the stresses in disc components are illustrated during the sudden overload, demonstrating that due to the loss of load bearing capacity of cancellous bone, the load transfer through the vertebra and disc moves from inside to outside. 


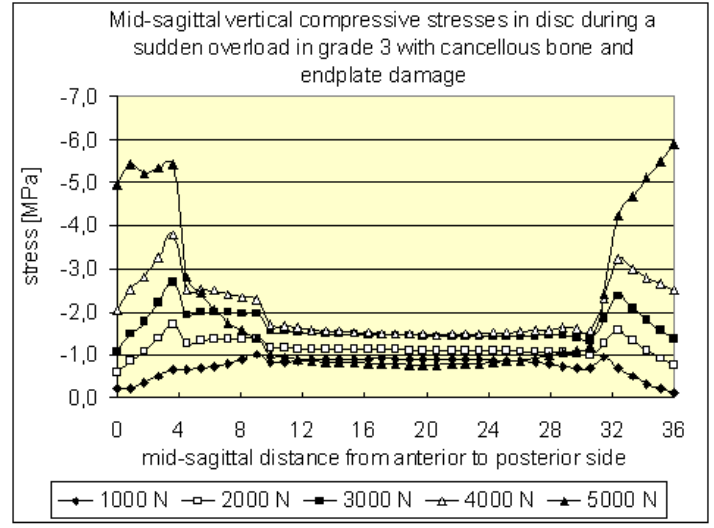

a)

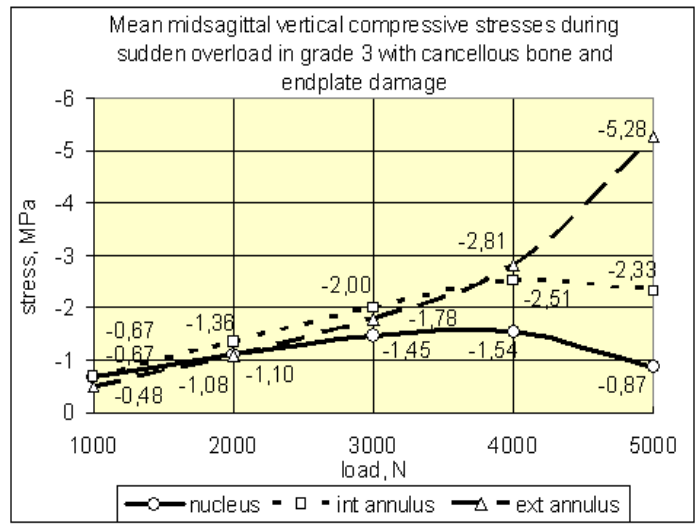

b)

Figure 8. a) Mid-sagittal vertical compressive stress distribution in disc when the sudden overload happens in older age, in grade 3 with cancellous bone and endplate damage; b) the relating vertical compressive stresses

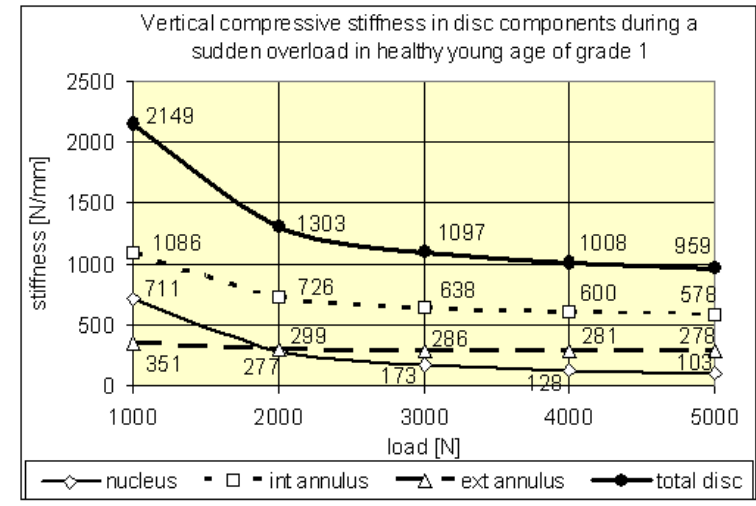

a)

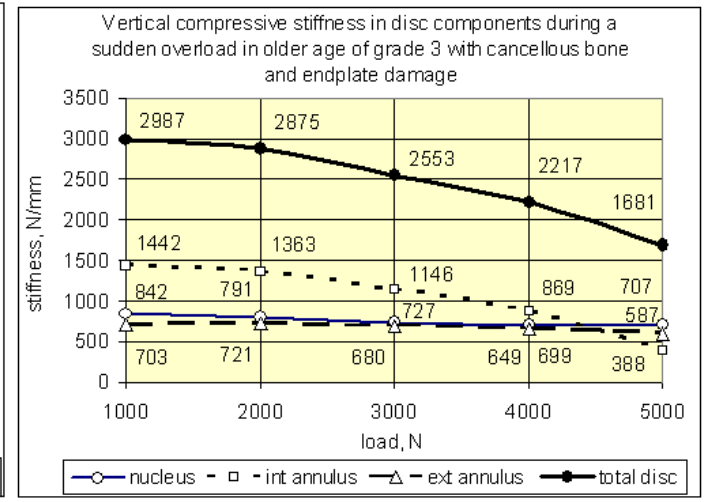

b)

Figure 9. Stiffness loss of disc components during the sudden overload in the case of a) young age of grade 1 and b) older age of grade 3

Figure 9 shows the sudden stiffness loss of disc components during the sudden overload for grade 1 of young age and for grade 3 of older age. Observe that the stiffness decrease in young age starts from a lower level than in older age and consequently tends to a lower level. On the other hand, the gradient of fall of stiffness is more rapid in young age than in older age.

\section{Discussion and conclusion}

By numerical simulation the separated effect of the two main factors of age-related disc degenerations, the gradual loss of incompressibility and the gradual increasing stiffness of nucleus can be modeled numerically by gradually decreasing Poisson's ratio and increasing Young's modulus of nucleus respectively. ${ }^{37}$ In the first period of aging degeneration process the loss of incompressibility, later the stiffening of nucleus has the dominant effect on the deformability and stresses of disc (Figures 2 and 3). The reason of this phenomenon lays on the fact that the nucleus 
is fluid-like only in young age, so it is obvious that the effect of loss of hydrostatics can be related to the first period of aging. ${ }^{6-7}$

During the aging degeneration the vertical load transfer moves from inside to outside, it tends to the external annulus (Figure 3b). Indeed, Adams et al. ${ }^{3,31}$ obtained experimentally that the vertical compressive stress decreases int he nucleus and increases in the external annulus during aging degeneration.

The compressive stiffness of the whole disc is minimum in mildly degenerated state, and duribg further aging the stiffness of the disc strongly increases. leading to the risk of instability and injury in young age (Figure 5). Schmidt et al. ${ }^{14}$ found that the disc prolapse initially increased for mildly degenerated state, and subsequently decreased for moderately and severely degenerated discs. Tang et al. ${ }^{9}$ concluded that light degeneration of disc leaded to instability, while the stability restored with further degeneration. Adams et al. $^{3}$ found that lower lumbar discs which appeared to prolapse were non-degenerated of cadavers aged 40-50 years; severely degenerated discs could not be made to prolapse.

During sudden overload-related nucleus degeneration in young age, due to the sudden loss of nucleus incompressibility, the support of the internal annulus disappears, causing buckle in the annulus layers, thus, the load transfer moves dominantly to the external annulus (Figure 6 ) yielding strong increase in disc shortening and bulging, however, if the sudden overload happens in older age, these effects are smaller (Figure 7).

While during the age-related degeneration process the compressive stiffness of the disc increases, during the overload-related sudden process, the stiffness strongly decreases (Figures 5 and 9). Also in sudden degeneration the smallest stiffness belongs to the weakly degenerated state in young age since in this case the sudden stiffness loss starts at the smallest stiffness level. In older age, the sudden stiffness loss starts at a higher stiffness level (Figure 9). The gradient of sudden stiffness loss is also stronger in younger age.

We have proved by numerical analysis that younger segments are the most vulnerable during both long-time age-related and sudden overload-related degeneration. Several recent studies ${ }^{3-5,9-10}$ concluded that light degeneration of disc in young age leaded to instability of lumbar spine, since the lightly degenerated discs had the smallest stiffness. These effects explain why are the young adults who suffer so frequently by low back pain problems.

\section{REFERENCES}

1. Adams MA, Freeman BJ, Morrison HP, Nelson IW, Dolan P. Mechanical initiation of intervertebral disc degeneration, Spine, 2000;25(13):1625-36.

2. Ferguson SJ, Steffen T. Biomechanics of aging spine, Eur.Spine J. 203;12(2):97-103.

3. Adams MA, Bogduk N, Burton K, Dolan P. The Biomechanics of Back Pain, Churchill Livingstone, Edinburgh, London, New York, Oxford, Philadelphia, 2002 p. 238.

4. Rohlmann A, Zander T, Schmidt H, Wilke HJ, Bergmann G. Analysis of the influence of disc degeneration on the mechanical behaviour of a lumbar motion segment using the finite element method, J. of Biomechanics, 2006;39(13):2484-90. 
5. Schmidt H, Heuer F, Simon U, Kettler A, Rohlmann A, Claes L, Wilke HJ. Application of a new calibration method for a three-dimensional finite element model of a human lumbar annulus fibrosus, Clinical Biomechanics, 2006;21(4):337-44.

6. Iatridis JC, Wedenbaum M, Setton LA, Mow VC. Is the nucleus pulposus a solid or a fluid? Mechanical behaviours of the nucleus pulposus of the human intervertebral disc, Spine, 1996;21(10): 1174-84.

7. Iatridis JC, Setton LA, Wedenbaum M, Mow VC. Alterations in the mechanical behavior of the human lumbar nucleus pulposus with degeneration and aging. J. of Orthopaedic Research, 1997;15(2):318-22.

8. Polikeit A, Nolte LP, Ferguson SJ. Simulated influence of osteoporosis and disc degeneration on the load transfer in a lumbar functional spinal unit, J. of Biomechanics, 2004;37(7):1061-9.

9. Tang XJ, Chen QX, Liu YS, Li FC. Analysis of lumbar disc degeneration using three-dimensional nonlinear finite element method, (Article in Chinese), Zhonghua Yi Xue Za Zhi, 2008;88(23):1634-8.

10.Schmidt H, Kettler A, Rohlmann A, Claes L, Wilke HJ. The risk of disc prolapses with complex loading in different degrees of disc degeneration - a finite element analysis, Clinical Biomechanics, 2007;22(9),988-98.

11. Schmidt H, Heuer F, Wilke HJ. Dependency of disc degeneration on shear and tensile strains between annular fiber layers for complex loads, Medical Eng. Physics, 2009;31(6):642-9.

12. Laible JP, Pflaster DS, Krag MH, Simon BR, Haugh LD. A poroelastic finite element model with application to the intervertebral disc. Spine, 1993;18(5):659-70.

13. Natarajan RN, Williams JR, Andersson GB. Modeling changes in intervertebral disc mechanics with degeneration, J. of Bone and Joint Surgery Am. 2006;88(4):36-40.

14.Schmidt H, Kettler A, Rohlmann A, Claes L, Wilke HJ. The risk of disc prolapses with complex loading in different degrees of disc degeneration - a finite element analysis, Clinical Biomechanics, 2007;22(9):988-98.

15. Denoziere G. Numerical modeling of ligamentous lumbar motion segment, Master thesis, Georgia Institute of Technology, 2004.

16. Panjabi MM, Oxland T, Takata K, Goel V, Duranceau J, Krag M. Articular facets of the human spine, quantitative three dimensional anatomy, Spine, 1993;18(10):1298-1310.

17. Denoziere G, Ku DN. Biomechanical comparison between fusion of two vertebrae and implantation of an artificial intervertebral disc, J. of Biomechanics, 2006;39(4):766-75.

18. Rohlmann A, Zander T, Schmidt H, Wilke HJ, Bergmann G. Analysis of the influence of disc degeneration on the mechanical behaviour of a lumbar motion segment using the finite element method, J. of Biomechanics, 2006;39(13):2484-90.

19. Schmidt H, Heuer F, Simon U, Kettler A, Rohlmann A, Claes L, Wilke HJ. Application of a new calibration method for a three-dimensional finite element model of a human lumbar annulus fibrosus, Clinical Biomechanics, 2006;21(4):337-44.

20. Rohlmann A, Bauer L, Zander T, Bergmann G, Wilke HJ. Determination of trunk muscle forces for flexion and extension by using a validated finite element model of the lumbar spine and measured in vivo data, J. of Biomechanics, 2006;39(6):981-9.

21. Noailly J, Wilke HJ, Planell JA, Lacroix D. How does the geometry affect the internal biomechanics of a lumbar spine bi-segment finite element model? Consequences on the validation process, J. of Biomechanics, 2007;40(11):2414-25.

22. Shirazi-Adl SA, Shrivastava SC, Ahmed AM. Stress analysis of the lumbar disc-body unit in compression. A three-dimensional nonlinear finite element study, Spine, 1984;9(2):120-34.

23. Shirazi-Adl A. Strain in fibers of a lumbar disc. Analysis of the role of lifting in producing disc prolapse, Spine, 1989;14(1):96-103. 
24. Spilker RL, Jakobs DM, Schultz AB. Material constants for a finite element model of the intervertebral disc with a fibre composite annulus, J. of Biomechanical Eng. 1986;108(1):1-11.

25. Rao AA, Dumas GA. Influence of material properties on the mechanical behaviour of the L5-S1 intervertebral disc in compression: a nonlinear finite element study, J. of Biomedical Eng. 1991;13(2):139-51.

26. Goel VK, Kong W, Han JS, Weinstein JN, Gilbertson LG. A combined finite elelement and optimization investigation of lumbar spine mechanics with and without muscles. Spine, 1993;18(11):1531-41.

27. Lavaste F, Skalli W, Robin S, Roy-Camille R, Mazel C. Three-dimensional geometrical and mechanical modelling of lumbar spine, J. of Biomechanics, 1992;25(10):1153-64.

28. Zander T, Rohlmann A, Bergmann G. Influence of ligament stiffness on the mechanical behaviour of a functional spinal unit, J. of Biomechanics, 2004;37(7):1107-11.

29. Kurowski P, Kubo A. The relationship of degeneration of the intervertebral disc to mechanical loading conditions on lumbar vertebrae, Spine, 1986;11(7):726-31.

30. McNally DS, Adams MA. Internal intervertebral disc mechanics as revealed by stress profilometry, Spine, 1992;17(1):66-73.

31. Adams MA, McNally DS, Dolan P. Stress distributions inside intervertebral discs. The effects of age and degeneration. J. Bone Joint Surg. Br. 1996;78(6):965-72.

32. Kurutz M, Bene É, Lovas A. In vivo deformability of human lumbar spine segments in pure centric tension, measured during traction bath therapy, Acta of Bioengineering and Biomechanics, 2003;5(1):67-92.

33. Kurutz M, Bender T. Weightbath hydrotraction treatment - application, biomechanics and clinical effects, J. of Multidisciplinary Healthcare, 2010;(3):19-27.

34. Dolan P, Adams MA. Recent advances in lumbar spinal mechanics and their significance for modeling, Clinical Biomechanics., 2001;16(1):8-16.

35. Cassinelli E, Kang JD. Current understanding of lumbar disc degeneration, Operative techniques in orthopaedics, 2000;10(4):254-62.

36. Little JP, Adam CJ, Evans JH, Pettet GJ, Pearcy MJ. Nonlinear finite element analysis of anular lesions in the L4/5 intervertebral disc, J. of Biomechanics, 2007;40(12):2744-51.

37. Kurutz M, Oroszváry L. Finite element analysis of weightbath hydrotraction treatment of degenerated lumbar spine segments in elastic phase. J. of Biomechanics, 2010;43(1):433-41.

The authors gratefully acknowledge the Hungarian Scientific Research Fund OTKA for providing financial support in the frame of the grant $K-075018$. 